\title{
Effect of chronic stress in newborn rats on the progression of ligature-induced- periodontitis in adulthood ${ }^{1}$
}

\author{
Tereza Aparecida Delle Vedove Semenoff', Aurélio Rosa Júnior"I, Álvaro Henrique Borges ${ }^{\mathrm{III}}$, Alessandra Nogueira Porto ${ }^{\mathrm{IV}}$, \\ Cervantes Caporossiv, Alex Semenoff Segundo ${ }^{\mathrm{VI}}$ \\ IPhD, Associate Professor, Master Program in Integrated Dentistry Science, Faculty of Dentistry, University of Cuiaba (UNIC), Cuiaba-MT, Brazil. \\ Conception and design of the study, acquisition and interpretation of data, manuscript writing.

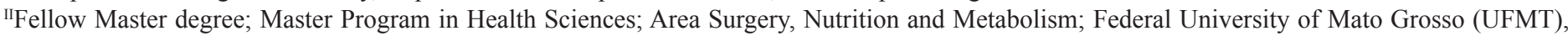 \\ Cuiaba-MT, Brazil. Acquisition and interpretation of data. \\ IIIPhD, Associate Professor, Master Program in Integrated Dentistry Science, Faculty of Dentistry, UNIC, Cuiaba-MT, Brazil. Manuscript preparation, \\ critical revision. \\ ${ }^{\text {IV }} \mathrm{PhD}$, Associate Professor, Master Program in Integrated Dentistry Science, Faculty of Dentistry, UNIC, Cuiaba-MT, Brazil. Manuscript writing, \\ critical revision. \\ ${ }^{\mathrm{V}} \mathrm{PhD}$; Associate Professor; Master Program in Health Sciences; Area Surgery, Nutrition and Metabolism; UFMT, Cuiaba-MT, Brazil. Supervised all \\ phases of the study, critical revision. \\ ${ }^{\mathrm{V}} \mathrm{PhD}$, Associate Professor, Master Program in Integrated Dentistry Science, Faculty of Dentistry, UNIC. Cuiaba-MT, Brazil. Intellectual and scientific \\ content of the study, final approval of the version to be published.
}

\section{ABSTRACT}

PURPOSE: To investigate the effect chronic stress in newborn rats on the progression of ligature-induced-periodontitis in adulthood.

METHODS: Ten couples of adult Wistar rats were selected for mating. After birth, the female and their respective offsprings were allocated into two groups. Ligature Group (LG): offsprings were only watched during breast-feeding; Stress-ligature Group (SLG): after $24 \mathrm{~h}$ of live birth, the offsprings were moved away from their mothers every day for four hours during breast-feeding for 20 days; in both approaches, after reaching $\pm 250 \mathrm{~g}$, ten rats were included in the groups. Periodontal disease was induced by a silk suture placed around the maxillary right second molar. The left side was used as control. After 15 days, the animals were subjected to euthanasia, maxillary bones were removed and stored in 10\% formaldehyde. After $48 \mathrm{~h}$, radiographs were taken and revealed and were used for bone destruction analysis. Examiner was blind and calibrated for measurements.

RESULTS: Stress-ligature group presented higher bone loss values in relation to ligature group ( $\mathrm{p}<0.05)$.

CONCLUSION: Exposure to chronic stress imposed on offsprings produced a greater progression of bone loss induced during adulthood.

Key words: Stress, Psychological. Periodontitis. Alveolar Bone Loss. Animals, Newborn. Rats. 


\section{Introduction}

Stress acts directly on the hypothalamus-pituitaryadrenal (HPA) axis, mainly on neuroendocrine and inflammatory responses $^{1}$. The effect related to these responses, in general, is to lower body's defenses ${ }^{1}$. Nevertheless, there is currently an attempt to modulate these defenses into a protective effect ${ }^{2}$. Overall, these effects make possible the onset or increase susceptibility to the establishment of several pathologies ${ }^{3}$. Among those are emotional ${ }^{4}$, infectious and inflammatory diseases ${ }^{1}$, and physical illness ${ }^{5}$.

In periodontics, the deleterious effects of chronic stress on the periodontum are $\mathrm{known}^{6}$, but such relationship is not recent. In current times, many epidemiological studies with different designs have pointed out the relationship between these two diseases ${ }^{7}$. In view of further elucidating the biological events involved, many studies use animals, particularly rats, to demonstrate immuneinflammatory aspects that contribute to the understanding of the pathogenesis of periodontal disease ${ }^{8,9}$.

Several studies in the medical field have modulated the pattern of disease progression by means of stress $^{1-3}$. Accordingly, there is a broad literature demonstrating an involvement of chronic stress during pregnancy or in the early childhood as one of the factors related to the onset of diverse diseases ${ }^{10}$. In dentistry, this area of study has begun to arouse attention. Some studies in rats show that the chemical modulation of the HPA axis, or directly the effect of physical chronic stress during pregnancy are responsible for a higher progression of periodontitis induced in adulthood ${ }^{11,12}$.

Thus, the aim of this paper was to verify if rats subjected to stress, that is, being moved away from their progenitors during infant stage, present greater alveolar bone loss in presence of ligature-induced periodontitis in adulthood.

\section{Methods}

Approved by the Ethics in Animal experimentation Committee of the School of Dentistry of Cuiaba, UNIC, Brazil (Process number \#2010-044).

Twenty Wistar rats (Rattus novergicus), ten female and ten male, were selected for the study.

Initially the animals weighing average $230 \mathrm{~g}$ were selected and allowed to adapt to the new environment for ten days. These animals were separated in groups of five animals and they were kept in a cage (polyethylene 16x40x30) with standard feed and water ad libitum, light/dark cycle of 12 hours. Temperature and humidity were controlled at $23^{\circ} \mathrm{C}$ and $\pm 40 \%$, respectively.

Experimental procedures and animals care were also performed in accordance with the European Convention for the Protection of Vertebrate animals used for Experimental and other scientific purposes.

Animals being three months of age were housed together (one male: one female) for mating. In order to determine the estrus cycle, we subjected the rats to a daily vaginal smear (7a.m). When screened animals were found to be in proestrus, they were housed individually overnight with a male rat. Vaginal samples were microscopically checked the next morning for verification of presence of sperm. The day when smear was sperm-positive was considered to be the embryonic day 0 .

After delivering, a number of eight animals was standardized per mother. On the day 1 after birth, the newborns of five mothers were assigned to the group stress ligature (SLG) and then removed from their mothers four hours per day for a 20-dayperiod.

The newborns from others five mothers were assigned to the group ligature (LG) and remained with their mothers throughout the 20-day-period.

After this period, the rats of both groups remained with their respective mothers throughout the period until weaning time.

Thus, the animals were separated by sex; 24 males were randomly selected and from each group (SLG $n=24)$ and (LG $\mathrm{n}=24)$

When $250 \mathrm{~g}$ of body weight (mean age of approximately 2.5 months) were reached, the animals were subjected to experimentally-induced periodontal disease. All procedures in this phase of the experiment were performed under general anaesthesia by means of intramuscular injection of a combination of $0.1 \mathrm{~mL}$ of ketamine hydrochloridea and $0.05 \mathrm{~mL}$ of xylazine hydrochloridea for each $100 \mathrm{~g}$ of body weight.

After anesthesia, sterile 4/0 silk ligatures were placed around the maxillary right second molar. The maxillary left second molar was used as control. The animals were sacrificed by anesthetic overdose 15 days after receiving the ligatures.

Right and left hemimaxillae were fixed in 10\% formalin solution for $48 \mathrm{~h}$. Radiographs were taken using a dental X-ray unit (Specto x70, Dabi Atlante, Ribeirao Preto-SP, Brazil). To take the images, specimens were placed on the film (Kodak insight dental film, Sao Paulo-SP, Brazil), and the X-ray cone was set perpendicular to it. The distances between the cone and the specimens as well as an exposure time of $0.3 \mathrm{~s}$ were standardized based on a previous pilot study. A trained operator processed all radiographs using the same time and temperature.

Order to better understanding of the study design the Figure 1 was prepared. 


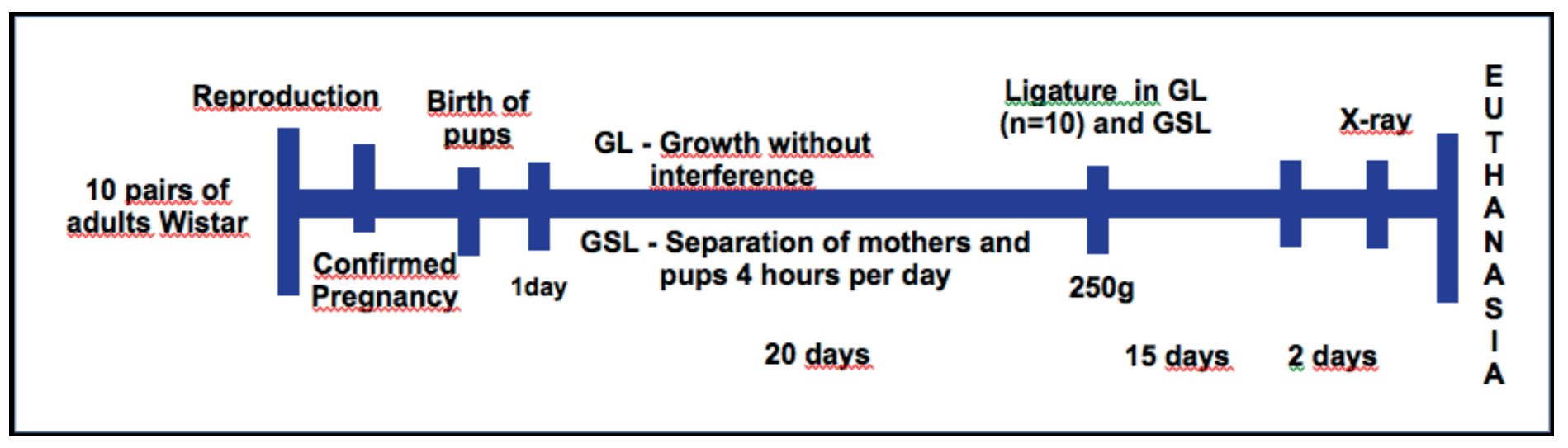

FIGURE 1 - Study design.

Radiographs were projected on a white board using a slide projector (Kodak-Ektagraphic III, Sao Paulo-SP, Brazil) that provided a 15 -fold magnification of the images. Then, after identifying the structures between the first and second molars, the teeth and interproximal bone crest were drawn on the board, as well as a horizontal line between the cusp tips of both teeth. At the contact point between the molars, a vertical line perpendicular to the horizontal line was drawn. The distance between the bone crest and the horizontal line was determined by means of digital calipers (Paquimetro Digital, Mitsu, Sao Paulo-SP, Brazil) and recorded for further analysis and comparisons. A previously calibrated and blinded operator performed all measurements.

Data were statistically analyzed using Student's $t$ test for independent samples at 5\% significance level on SPSS software.

\section{Results}

The findings showed that SLG - composed by offsprings subjected to the chronic stress and ligature produced greater bone loss than LG - consisting by offsprings that were not stressed and subjected only ligature $(\mathrm{p}<0.05)$. The side including the control group displayed no disease progression $(\mathrm{p}>0.05)$ - Table 1 .

TABLE 1 - Means and standard deviations of the groups Ligature and Stress-plus-Ligature.

\begin{tabular}{|c|c|c|c|c|}
\hline Groups & Right Side & $\mathbf{n}$ & Mean & Std. deviation \\
\hline \multirow{2}{*}{$\begin{array}{l}\text { Test } \\
\text { Side }\end{array}$} & SLG & 10 & $20.80 *$ & 1.03 \\
\hline & LG & 9 & $17.33 *$ & 3.46 \\
\hline \multirow{3}{*}{$\begin{array}{l}\text { Control } \\
\text { Side }\end{array}$} & Left Side & & & \\
\hline & SLG & 10 & 13.04 & 0.80 \\
\hline & LG & 9 & 12.90 & 0.97 \\
\hline
\end{tabular}

Student's t test for independent samples. *means $\mathrm{p}<0.05$.

\section{Discussion}

There have been a substantial number of scientific evidences establishing the nexus between periodontitis and chronic stress ${ }^{6,8,9,13}$. In addition, observational studies in humans have pointed out this same relationship, but with poor information regarding biological events ${ }^{7}$. Despite this, we still lack the establishment of stress as a risk factor ${ }^{14}$ as occurs, for instance, to diabetes and tobacco ${ }^{15}$.

As regards ligature-induced periodontitis in rats and chemical modulation or physical stress at an early age, two studies presented findings and designs similar to those found in the present investigation. The first was aimed in early childhood to use drugs that might interfere with the neurophysiology of the HPA axis in adulthood. This factor was decisive in establishing a change in the susceptibility to the illness, leading to disease progression in the periodontum during adulthood ${ }^{12}$. Other relevant issues were the behavioral and hormone tests; both confirmed alterations in the physiology of the HPA axis. The second investigation following this same line of research, but with mother rats being subjected to physical stress during pregnancy, showed that their offsprings in adulthood had greater bone loss when compared to the control group $^{11}$.

At the present time, there are a reasonable number of studies demonstrating that manipulation of the HPA axis can either lead to greater progression of periodontitis ${ }^{16}$ or prevent its progression $^{17}$. In this sense, other evidences have indicated that this manipulation could start, perhaps in the near future, even before birth. It is emphasized that this step of science is still far, though neuroendocrine manipulation seems possible. Several trials in humans have already manipulated the limbic system in order to improve responses upon the challenges of diseases ${ }^{1-3}$. Nowadays, this designation is named the programming factor, so it seems that one can think of this effect in relation to the etiopathogenesis of periodontitis ${ }^{18}$. 
Even though the structures of the HPA axis are already formed in newborns, there is still no complete formation of the anatomical structures of the limbic system and autonomous system ${ }^{19}$. At this point, the stress of maintaining the progeny away from the mother seems to stimulate increased secretion of glucocorticoids that can affect the natural development of the $\operatorname{animal}^{20}$.

The anatomical and chemical manipulations of the hypothalamic-pituitary-adrenal (HPA) axis enable the modulation of response through an immune-inflammatory process linked to periodontitis ${ }^{16,17}$. Among the systemic alterations there are changes occurred in the paraventricular nucleus (PVN), connected directly to nerve cells responsible for producing neurohormones such as adrenocorticotropic hormone $(\mathrm{ACTH})^{1}$ and corticotropinreleasing hormone $(\mathrm{CRH})$. It is important to explain that the manipulation of these structures may alter beyond the immuneinflammatory response of the periodontum, producing changes in glucose levels, growth of the adrenal gland, pancreas alterations, in addition to cognitive changes ${ }^{20}$. Furthermore, stress can lead to a decreased amount of oxygen in the arteries, which can hinder brain development, interfering with neuroendocrine responses of the body ${ }^{19}$.

The present study verified if rats undergoing stress, that is, progenitor moving away in infant stage, would have their offsprings presenting higher alveolar bone loss in presence of ligature-induced periodontitis during adulthood. Our data demonstrated that offsprings of rats that were stressed during infant stage had a greater bone loss progression during adulthood.

Currently, the impact of physical or chemical stress during childhood or pregnancy on adulthood is known in many areas of health ${ }^{10,12}$. In this respect, most of the information regarding biological events has been acquired through animals. Another relevant point refers to controls of biases in human behavior; in animals, that control is possible. Also, it is noteworthy that rats have low costs and easy handling, but require aids with regard to ethical issues $^{8,9}$.

Although the results are interesting, further information on this topic is needed, so that in a near future human beings can get responses that contributes to their health.

\section{Conclusion}

Exposure of rats to chronic stress, move away from their progenitors during infant stage, produced a greater progression of bone loss induced in the adult offsprings.

\section{References}

1. Moynihan JA Mechanisms of stress-induced modulation of immunity. Brain Behav Immun. 2003;17 Suppl 1:S11-6.

2. Webber MA. Psychoneuroimmunological outcomes and quality of life. Transfus Apher Sci. 2010;42(2):157-61.

3. Fujioka A, Fujioka T, Ishida Y, Maekawa T, Nakamura S. Differential effects of prenatal stress on the morphological maturation of hippocampal neurons. Neuroscience. 2006;141(2):907-15.

4. Fazel S, Danesh J. Serius mental disorder in 23000 prisoners: a systematic review of 62 surveys. Lancet. 2002;359(9306):545-50.

5. Tausk F, Elenkov I, Moynihan J. Psychoneuroimmunology. Dermatol Ther. 2008;21(1):22-31.

6. Semenoff-Segundo A, Porto AN, Semenoff TA, Cortelli JR, Costa FO, Cortelli SC, Bosco AF. Effects of two chronic stress models on ligature-induced periodontitis in Wistar rats. Arch Oral Biol. 2012;57(1):66-72.

7. Genco RJ, Ho AW, Grossi SG, Dunford RG, Tedesco LA. Relationship of stress, distress and inadequate coping behaviors to periodontal disease. J Periodontol. 1999;70(7):711-23.

8. Peruzzo DC, Benatti BB, Antunes IB, Andersen ML, Sallum EA, Casati MZ, Nociti FH, Nogueira-Filho GR. Chronic stress may modulate periodontal disease: a study in rats. J Periodontol. 2008;79(4):697-704.

9. Segundo AS, Hennemann K, Fontanella VR, Rösing CK. The role of psychoneuroimmune interactions in the pathogenesis of ligatureinduced periodontal disease in Wistar rats. J Int Acad Periodontol. 2007;9(1):26-31.

10. Christian LM. Psychoneuroimmunology in pregnancy: Immune pathways linking stress with maternal health, adverse birth outcomes, and fetal development. Neuroscience Biobehav Rev. 2012;36(1):350-61.

11. Semenoff-Segundo A, Delle Vedove Semenoff TA, Borges ÁH, Pedro FL, Caporossi LS, Bosco ÁF. The influence of chronic stress imposed on pregnant rats on the induced bone loss in their adult offspring. Arch Oral Biol. 2012;57(5):477-82.

12. Breivik T, Stephan M, Brabant GE, Straub RH, Pabst R, von Hörsten S. Postnatal lipopolysaccharide-induced illness predisposes to periodontal disease in adulthood. Brain Behav Immun. 2002;16(4):421-38.

13. Peruzzo DC, Benatti BB, Ambrosano GM, Nogueira-Filho GR, Sallum EA, Casati MZ, Nociti FH Jr. A systematic review of stress and psychological factors as possible risk factors for periodontal disease. J Periodontol. 2007;78(8):1491-504.

14. Nakajima K, Hamada N, Takahashi Y, Sasaguri K, Tsukinoki K, Umemoto T, Sato S. Restraint stress enhances alveolar bone loss in an experimental rat model. J Periodontal Res. 2006;41(6):527-34.

15. Silva AM, Vargas AM, Ferreira EF, de Abreu MH. Periodontitis in individuals with diabetes treated in the public health system of Belo Horizonte, Brazil. Rev Bras Epidemiol. 2010;13(1):118-25.

16. Breivik T, Opstad PK, Gjermo P, Thrane PS. Effects of hypothalamicpituitary-adrenal axis reactivity on periodontal tissue destruction in rats. Eur J Oral Sci. 2000;108(2):115-22.

17. Breivik T, Gundersen Y, Myhrer T, Fonnum F, Osmundsen H, Murison R, Gjermo P, von Hórsten S, Opstad PK. Enhanced susceptibility to periodontitis in an animal model of depression: reversed by chronic treatment with the anti-depressant tianeptine. J Clin Periodontol. 2006;33(7):469-77.

18. Bosch OJ, Müsch W, Bredewold R, Slattery DA, Neumann ID. Prenatal stress increases HPA axis activity and impairs maternal care in lactating female offspring: implications for postpartum mood disorder. Psychoneuroendocrinology 2007;32(3):267-78. 
19. Fan JM, Chen XO, Jin H, Du JZ. Gestational hypoxia alone or combined with restraint sensitizes the hypothalamic-pituitaryadrenal axis and induces anxiety-like behavior in adult male rat offspring. Neuroscience 2009;159(4):1363-73.

20. Maccari S, Morley-Fletcher S. Effects of prenatal restraint stress on the hypothalamus-pituitary-adrenal axis and related behavioral and neurobiological alterations Psychoneuroendocrinology 2007;32 Suppl1:S10-5.

\section{Correspondence:}

Tereza Aparecida Delle Vedove Semenoff

Rua Professora Azélia Mamoré de Melo, 318/63

78005-700 Cuiabá - MT Brasil

Tel.: (55 65) 3322-8390/8113-1777

t.semenoff@uol.com.br

Received: May 27, 2013

Review: July 25, 2013

Accepted: Aug 22, 2013

Conflict of interest: none

Financial source: University of Cuiaba (UNIC)

${ }^{1}$ Research performed at Laboratory of Master Program in Integrated Dentistry Science, Faculty of Dentistry, University of Cuiaba (UNIC), Cuiaba-MT, Brazil. 